\title{
Electrical conductivity and oxygen exchange kinetics of La2NiO4+delta thin films grown by chemical vapor deposition
}

Garcia, G.; Burriel, M.; Bonanos, Nikolaos; Santiso, J.

Published in:

Journal of the Electrochemical Society

Link to article, DOI:

$10.1149 / 1.2829900$

Publication date:

2008

Document Version

Publisher's PDF, also known as Version of record

Link back to DTU Orbit

Citation (APA):

Garcia, G., Burriel, M., Bonanos, N., \& Santiso, J. (2008). Electrical conductivity and oxygen exchange kinetics of La2NiO4+delta thin films grown by chemical vapor deposition. Journal of the Electrochemical Society, 155(3), P28-P32. https://doi.org/10.1149/1.2829900

\section{General rights}

Copyright and moral rights for the publications made accessible in the public portal are retained by the authors and/or other copyright owners and it is a condition of accessing publications that users recognise and abide by the legal requirements associated with these rights.

- Users may download and print one copy of any publication from the public portal for the purpose of private study or research.

- You may not further distribute the material or use it for any profit-making activity or commercial gain

- You may freely distribute the URL identifying the publication in the public portal 


\title{
Electrical Conductivity and Oxygen Exchange Kinetics of $\mathrm{La}_{2} \mathrm{NiO}_{4+\delta}$ Thin Films Grown by Chemical Vapor Deposition
}

\author{
Gemma Garcia, ${ }^{\mathrm{a}, \mathrm{z}}$ Mónica Burriel, ${ }^{\mathrm{b}, \mathrm{c}}$ Nikolaos Bonanos, ${ }^{\mathrm{d}}$ and José Santiso ${ }^{\mathrm{b}, \mathrm{c}}$ \\ ${ }^{a}$ Grup de Nanomaterials i Microsistemes, Unitat de Fisica de Materials I, Departament de Física, Universitat \\ Autònoma de Barcelona, 08193 Bellaterra, Spain \\ ${ }^{b}$ Institut de Ciencia de Materials de Barcelona, and ${ }^{c}$ Instituto de Nanociencia y Nanotecnología, Consejo \\ Superior de Investigaciones Cientificas, Esfera Universitat Autònoma de Barcelona, 08193 \\ Bellaterra, Spain \\ ${ }^{d}$ Fuel Cells and Solid State Chemistry Department, Risф National Laboratory, Technical University of \\ Denmark, 4000 Roskilde, Denmark
}

\begin{abstract}
Epitaxial $c$-axis oriented $\mathrm{La}_{2} \mathrm{NiO}_{4+\delta}$ films were deposited onto $\mathrm{SrTiO}_{3}$ and $\mathrm{NdGaO}_{3}$ substrates by the pulsed injection metal organic chemical vapor deposition technique. Experimental conditions were optimized in order to accurately control the composition, thickness, and texture of the layers. X-ray diffraction was used to confirm the high crystalline quality of the obtained material. Electrical characterizations were performed on thin $(50 \mathrm{~nm})$ and thick $(335 \mathrm{~nm})$ layers. The total specific conductivity, which is predominantly electronic, was found to be larger for the thinner films measured (50 nm), probably due to the effect of the strain present in the layers. Those thin films $(50 \mathrm{~nm})$ showed values even larger than those observed for single crystals and, to our knowledge, are the largest conductivity values reported to date for the $\mathrm{La}_{2} \mathrm{NiO}_{4+\delta}$ material. The oxygen exchange kinetics was studied by the electrical conductivity relaxation technique, from which the surface exchange coefficient was determined. (c) 2008 The Electrochemical Society. [DOI: 10.1149/1.2829900] All rights reserved.
\end{abstract}

Manuscript submitted September 21, 2007; revised manuscript received November 6, 2007.

Available electronically January 15, 2008

The preparation of thin films of materials with both high ionic and electronic conductivity is a major objective to achieve optimum performance in different electrochemical devices, such as solid oxide fuel cells, ${ }^{1}$ gas sensors, oxygen membrane generators, catalytic oxidation systems, etc. Particularly, mixed ionic-electronic conductor (MIEC) oxides with high oxygen reduction kinetics are needed in order to reduce solid oxide fuel cell (SOFC) operating temperatures. Nevertheless, studies concerning the chemical reaction kinetics of new oxides are generally performed on polycrystalline or even porous materials. In those materials some morphological aspects, such as particle size, grain boundary densities, shape, and connectivity, as well as porosity, which are known to enhance gas diffusion, may render the proper analysis of kinetic data difficult. On the contrary, studies performed on epitaxial MIEC thin films permit a more fundamental insight of the material's intrinsic properties, ${ }^{1,2}$ with the advantage of being closer to the planar geometry necessary to tackle practical applications. In the last decades, transition metal oxides with perovskite-related structures such as $\mathrm{La}_{2} \mathrm{NiO}_{4+\delta}(\mathrm{LNO})$ have shown high oxygen diffusivities and high electronic conductivities at high temperatures, ${ }^{3-8}$ making them attractive candidates for their use in electrochemical devices. Actually, LNO presents the advantage of having a thermal expansion coefficient close to the commonly used SOFC electrolytes, such as yttria-stabilized zirconia, $(\mathrm{La}, \mathrm{Sr})(\mathrm{Ga}, \mathrm{Mg}) \mathrm{O}_{3}$, and gadolinia-doped ceria. $\mathrm{La}_{2} \mathrm{NiO}_{4+\delta}$, with a $\mathrm{K}_{2} \mathrm{NiF}_{4}$ structure, can be described as a sequence of perovskite $\mathrm{LaNiO}_{3}$ layers alternated with rock-salt-type LaO layers along the $c$ axis. The enhanced oxygen conductivity of such structures was found to be related to their high oxygen hyperstoichiometry $(0 \leq \delta \leq 0.2)$, resulting from the incorporation of interstitial oxygen anions into the rock-salt-type layers. ${ }^{9}$ Because oxygen ionic transport in such compounds occurs mainly via diffusion along the interstitial sites, higher transport is expected along the $a-b$ planes in comparison to the $c$ direction, as assessed by theoretical simulations ${ }^{10}$ and evidenced by experimental measurements. ${ }^{11,12}$ The same anisotropy induced by the layered structure occurs for the electronic transport. ${ }^{13,14}$ Due to this large anisotropy, application of this material strongly depends on the capability of preparing it in a highly textured or epitaxial form. Studies concerning the preparation of lanthanum nickelate thin films and membranes are rather scarce. Sol-gel ${ }^{5-17}$ and spray pyrolisis ${ }^{18}$ techniques have been used to prepare polycrystalline $\mathrm{La}_{2} \mathrm{NiO}_{4+\delta}$ films, while nebulized spray

${ }^{\text {z }}$ E-mail: gemma@vega.uab.es pyrolisis, ${ }^{19}$ pulsed laser deposition, ${ }^{7,20,21}$ and the liquid pulsed injection metal organic chemical vapor deposition technique (PIMOCVD) $)^{22-24}$ were used to prepare highly textured layers. In this work, we present results on the preparation of epitaxial $\mathrm{La}_{2} \mathrm{NiO}_{4+\delta}$ thin films also by PIMOCVD onto $\mathrm{SrTiO}_{3}(100)$ and $\mathrm{NdGaO}_{3}(110)$ substrates. The deposition conditions were optimized in order to obtain fully oriented films with the $c$ axis perpendicular to the substrate surface. Planar electrical conductivity measurements along with conductivity relaxation experiments at high temperature were performed in order to analyze the oxygen exchange kinetics. Results are discussed as a function of temperature and film thickness.

\section{Experimental}

Films were grown in a PIMOCVD setup using solid $\beta$-diketonates $\mathrm{La}$ (thd) $)_{3}$ and $\mathrm{Ni}(\text { thd })_{2}$ (thd $=2,2,6,6$-tetramethylheptane-3,5-dionate) precursors from Strem Chemicals dissolved in 1,2-dimethoxyethane. The total concentration of the solution was $0.02 \mathrm{M}$, while the molar ratio $\mathrm{La} / \mathrm{Ni}$ in the precursor solution was equal to 3 . The evaporation and deposition temperatures were fixed at 280 and $750^{\circ} \mathrm{C}$, respectively, and the total gas flow was maintained at $1 \mathrm{~L} / \mathrm{h}$ with a 1:1 ratio of oxygen and argon. The opening time of the injector was $2 \mathrm{~ms}$ with a pulse frequency of $1 \mathrm{~Hz}$. Films were deposited on $\mathrm{SrTiO}_{3}(100)$ (noted STO) and $\mathrm{NdGaO}_{3}(110)$ (noted NGO) in order to promote epitaxial $c$-axis growth due to similar structural parameters. The structure and preferential orientation of the films was analyzed by X-ray diffraction (XRD) $[\lambda$ $=1.5418 \AA(\mathrm{Cu} \mathrm{K} \alpha)]$. The film thickness was determined by X-ray reflectometry and the film composition by microprobe analysis. The total conductivity along the $a-b$ plane was determined using an HP 4192A impedance analyzer at $1 \mathrm{kHz}$ frequency during the cooling process from $1015 \mathrm{~K}$ to room temperature and at $1 \mathrm{~atm}$ of pure oxygen. Two parallel Ag contacts were painted on the surface of the samples and used as probe contacts. In the electrical conductivity relaxation (ECR) experiments, for a constant temperature the sample was first held at equilibrium under an initial oxygen partial pressure and subsequently the gas atmosphere was abruptly switched to a different chosen oxygen partial pressure. The corresponding change in the conductivity of the sample, which reflects the change in its oxygen content, was recorded until a new equilibrium was established. By analyzing the normalized conductivity as a function of time $[g(t)]$ 


$$
g(t)=\left(\frac{\sigma(t)-\sigma_{0}}{\sigma_{\infty}-\sigma_{0}}\right)
$$

where $\sigma_{0}, \sigma_{\infty}$, and $\sigma(t)$ are the initial, final, and time $=t$ conductivity values, respectively, and solving Fick's second law for the given initial and boundary conditions, we obtained the chemical surface exchange coefficient, $k_{\mathrm{Ex}}$. In the case of surface exchange reaction control of the oxygen transport, according to the mass conversation law and assuming linear surface exchange kinetics, we have

$$
\frac{\partial c(t)}{\partial t}=-\frac{S}{V} k_{\mathrm{Ex}}[c(t)-c(\infty)]
$$

where $S$ and $V$ are the surface area and the volume of the film, respectively, $k_{\mathrm{Ex}}$ is the surface exchange coefficient, $c(t)$ is the oxygen concentration at time $t$, and $c(\infty)$ is the oxygen concentration at the new equilibrium.

As the measured $\mathrm{La}_{2} \mathrm{NiO}_{4+\delta}$ films were relatively thin $(<350 \mathrm{~nm})$ and largely below the characteristic thickness of the material determined by Kim et al., ${ }^{20}$ it was reasonable to assume that the oxygen transport was mainly controlled by the surface exchange rate. ${ }^{20}$ For a single surface reaction and a small oxygen pressure change, the normalized conductivity of a plane sheet is

$$
g(t)=1-\exp \left(-\frac{t}{\tau}\right)
$$

with

$$
\tau=\frac{l}{k_{\mathrm{Ex}}}
$$

where $\tau$ is the time constant and $l$ is the film thickness.

The oxygen partial pressure changes were performed by switching from an $\mathrm{O}_{2} / \mathrm{N}_{2}$ gas mixture with a $p_{\mathrm{O}_{2}}^{\prime}$ oxygen partial pressure to a gas mixture with a different oxygen content $p_{\mathrm{O}_{2}}^{\prime \prime}$. The oxygen concentration changes were controlled by two RAPIDOX 2000 oxygen sensors, situated before and after the exchange furnace. The oxygen pressure changes were fitted to an exponential equation, from which the finite flush time $\left(\tau_{\mathrm{f}}\right)$ was extracted. The extracted $\tau_{\mathrm{f}}$ had a value between 60 and $80 \mathrm{~s}$, depending on the temperature. For those cases where the oxygen partial pressure step change time was not negligible, we applied the flush time correction developed by Den Otter et al. $^{25}$ Electrical conductivity relaxation experiments were performed on two $c$-axis oriented epitaxial $\mathrm{La}_{2} \mathrm{NiO}_{4+\delta}$ thin films, 50 and $335 \mathrm{~nm}$ thick. Both reduction (from 1 to $0.50 \mathrm{~atm}$, from 0.50 to $0.25 \mathrm{~atm}$, and from 0.25 to $0.125 \mathrm{~atm} \mathrm{O}_{2}$ ) and oxidation (from 0.125 to $0.25 \mathrm{~atm}$, from 0.25 to $0.50 \mathrm{~atm}$, and from 0.50 to $1 \mathrm{~atm} \mathrm{O}_{2}$ ) processes were studied, performing sudden gas switches at 390, 480, 580 , and $660^{\circ} \mathrm{C}$ for both samples.

\section{Results and Discussion}

The general experimental conditions for the film deposition (total pressure of 10 Torr, valve opening time of $2 \mathrm{~ms}$, and injection frequency of $1 \mathrm{~Hz}$ ) were established by former studies performed with the same PIMOCVD equipment. ${ }^{26}$ Initial deposition tests starting from a $\mathrm{La} / \mathrm{Ni}$ solution ratio of 2.33 showed after wavelengthdispersive spectrometry analysis that $\mathrm{La} / \mathrm{Ni}$ in the solution had to be increased up to 3 to reach the expected $\mathrm{La} / \mathrm{Ni}$ value of 2 in the solid phase. The La/Ni ratio optimization details, as well as the XRD patterns of the different phases obtained by varying the La/Ni ratio in an extreme range, are described elsewhere. ${ }^{27}$ The deviation in the composition transfer between vapor and condensed phases is typical for MOCVD processes and occurs because each individual precursor has a different decomposition temperature which induces a different deposition yield for each element. The deposited lanthanum nickelates were nickel-rich compared with the injected precursor solution, as previously observed by Lane et al. in $\mathrm{LaNiO}_{3}$ layers ${ }^{28}$ and by Faucheux et al. in $\mathrm{La}_{2} \mathrm{NiO}_{4+\delta}$ layers. ${ }^{23}$ Increasing the deposition temperature gave rise to highly $c$-axis oriented $\mathrm{La}_{2} \mathrm{NiO}_{4+\delta}$

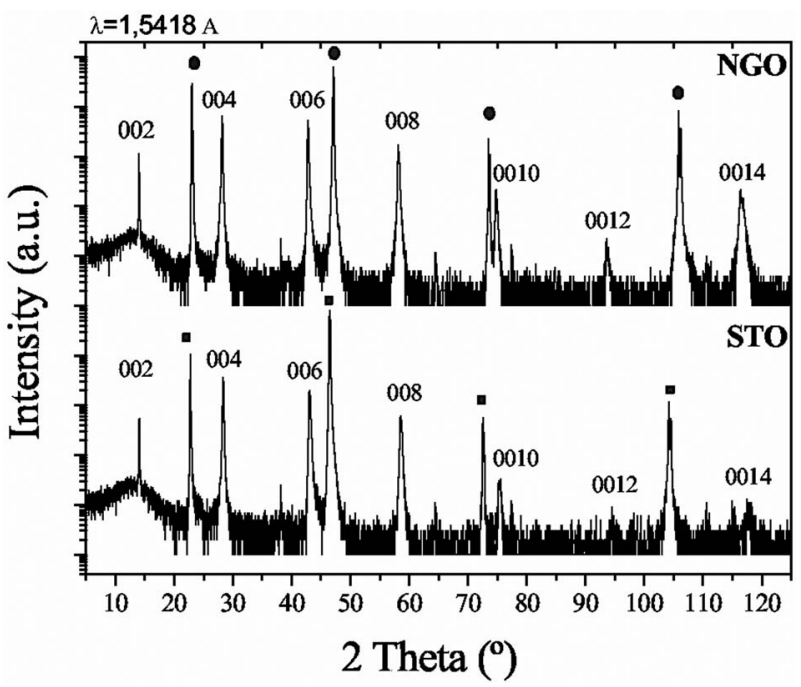

Figure 1. XRD patterns of thin films deposited on STO and NGO under the selected optimal conditions. The positions for substrate peaks: STO (squares) and NGO (circles) and of the $00 l$ peaks corresponding to $c$-axis oriented LNO are indicated.

phases, showing for films deposited around $750^{\circ} \mathrm{C}$ the narrowest XRD peaks and the best surface morphology uniformity. Films with different thickness were prepared, at these optimized conditions, by simply varying the number of droplets injected into the reactor. Film thickness was measured by X-ray reflectometry and the growth rate was estimated in $305 \mathrm{~nm} / \mathrm{h}$. The highly $c$-axis orientation of the layers was confirmed by XRD, as shown in the patterns in Fig. 1, in which, together with the substrate reflections, only the $00 l$ LNO reflections were detected. The narrow rocking curves [full width at half maximum $($ fwhm $)=0.2^{\circ}$ ] of the 008 reflection (Fig. 2a), that slightly broaden with film thickness, confirmed the high degree of

$\mathbf{a}$
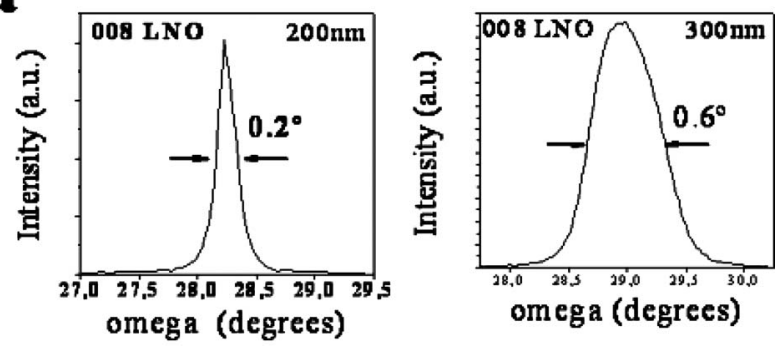

b

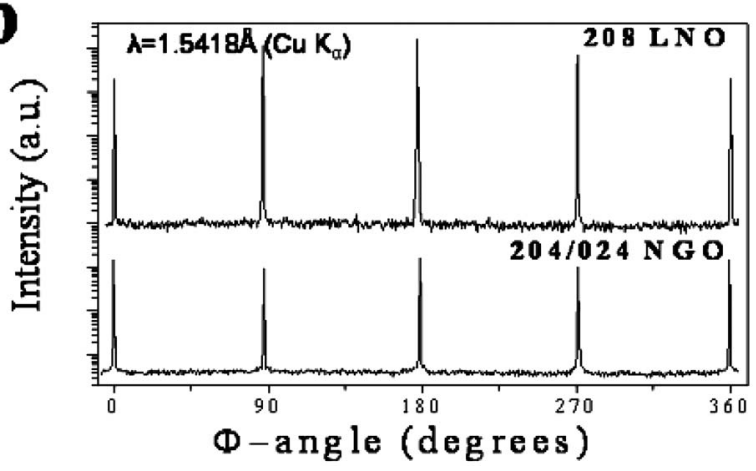

Figure 2. (a) X-ray rocking curve of the 008 reflection of a LNO layer grown on NGO of a thickness of 200 and $300 \mathrm{~nm}$, and (b) phi-scan of 200 nm thick LNO/NGO 208 reflection superimposed to the phi-scan of the 204/024 substrate reflection. 


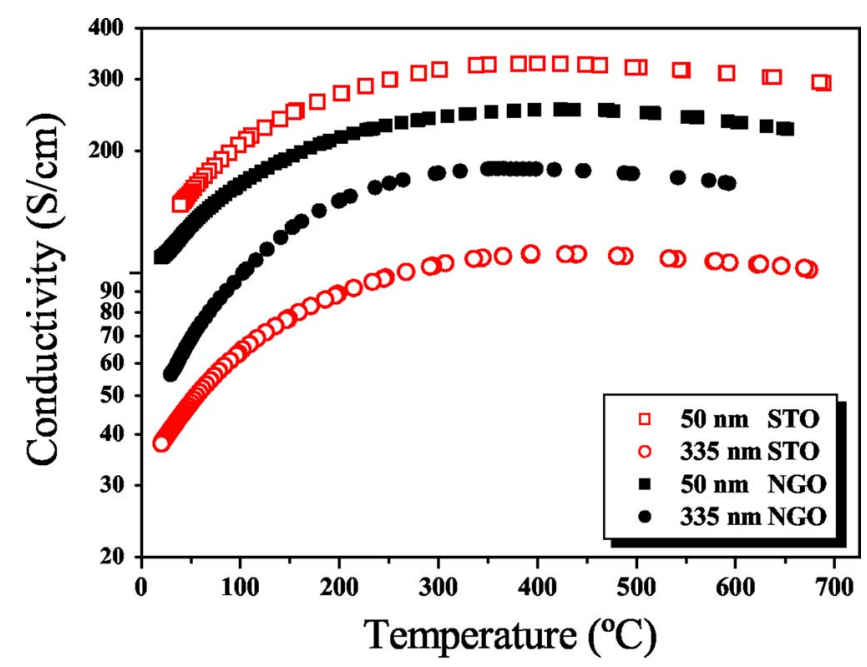

Figure 3. (Color online) Total conductivity measured during the cooling process of 50 and $335 \mathrm{~nm}$ thick LNO epitaxial films in oxygen atmosphere vs temperature.

orientation in the perpendicular direction. The orientation of the film slightly decreases when the film is grown on STO, as evidenced by a wider rocking curve of the 008 reflection $\left(\mathrm{fwhm}=0.78^{\circ}\right.$ for 325 $\mathrm{nm}$ thick films grown on STO compared to $0.63^{\circ}$ for $300 \mathrm{~nm}$ thick films grown on NGO substrate), which induces lower intensities of all $00 l$ diffraction peaks (Fig. 1). The fourfold symmetry observed in the phi-scan of the asymmetric 208 LNO reflection (Fig. 2b) and its relation with the 204 reflection phi-scan of the NGO substrate confirmed the perfect in-plane alignment of the film, which corresponded to the expected parallel arrangement of the perovskite blocks of the LNO structure onto those of the substrate. The surface roughness (roughness-mean-square) of the layers was relatively low, around $4 \mathrm{~nm}$ for the thin films and increased slightly up to $40 \mathrm{~nm}$ for the thicker films.

As films were $c$-axis oriented, the planar conductivity measurements reveal the transport properties along the $a-b$ plane. We have selected two extreme thicknesses, 50 and $335 \mathrm{~nm}$, deposited on STO and NGO substrates to study the influence of both thickness and strain on the total conductivity. The measured conductance of the substrates was found to be several orders of magnitude smaller than that of the layers and thus, the influence of the substrate conductivity could be neglected. In Fig. 3, in which the conductivity in $\mathrm{O}_{2}$ atmosphere is plotted as a function of temperature, we can observe that the total conductivity increases with temperature following a thermally activated behavior, reaching a maximum at around $400-450^{\circ} \mathrm{C}$. Above this temperature, the conductivity starts to decrease due to carrier depletion by oxygen loss from the film. ${ }^{4,27-29}$ Independently of the substrate used, the total conductivity of the thin samples is considerably higher than that of the thicker ones. The maximum conductivity was 252 and $327 \mathrm{~S} / \mathrm{cm}$ for the $50 \mathrm{~nm}$ films grown on NGO and STO, respectively, while for the thicker films the maximum conductivity value decreased to 180 and $110 \mathrm{~S} / \mathrm{cm}$ for the films grown on the same substrates. The differences in film orientation quality and in the strain induced by the film-substrate mismatch can generate microstructural differences as a function of the substrates used, which could be responsible for the conductivity differences between layers deposited on STO and NGO. These differences do not seem to follow the same behavior for thin and thick layers, as for the $50 \mathrm{~nm}$ layers the conductivity is higher for the film deposited on STO substrate, while the contrary occurs for the 335 $\mathrm{nm}$ layers, a fact for which we do not have a clear explanation. Nevertheless, all the $\mathrm{La}_{2} \mathrm{NiO}_{4+\delta}$ films presented higher conductivity values than those published for bulk polycrystalline samples, $, 8,30-35$ and the maximum conductivity close to $330 \mathrm{~S} / \mathrm{cm}$ was largely above
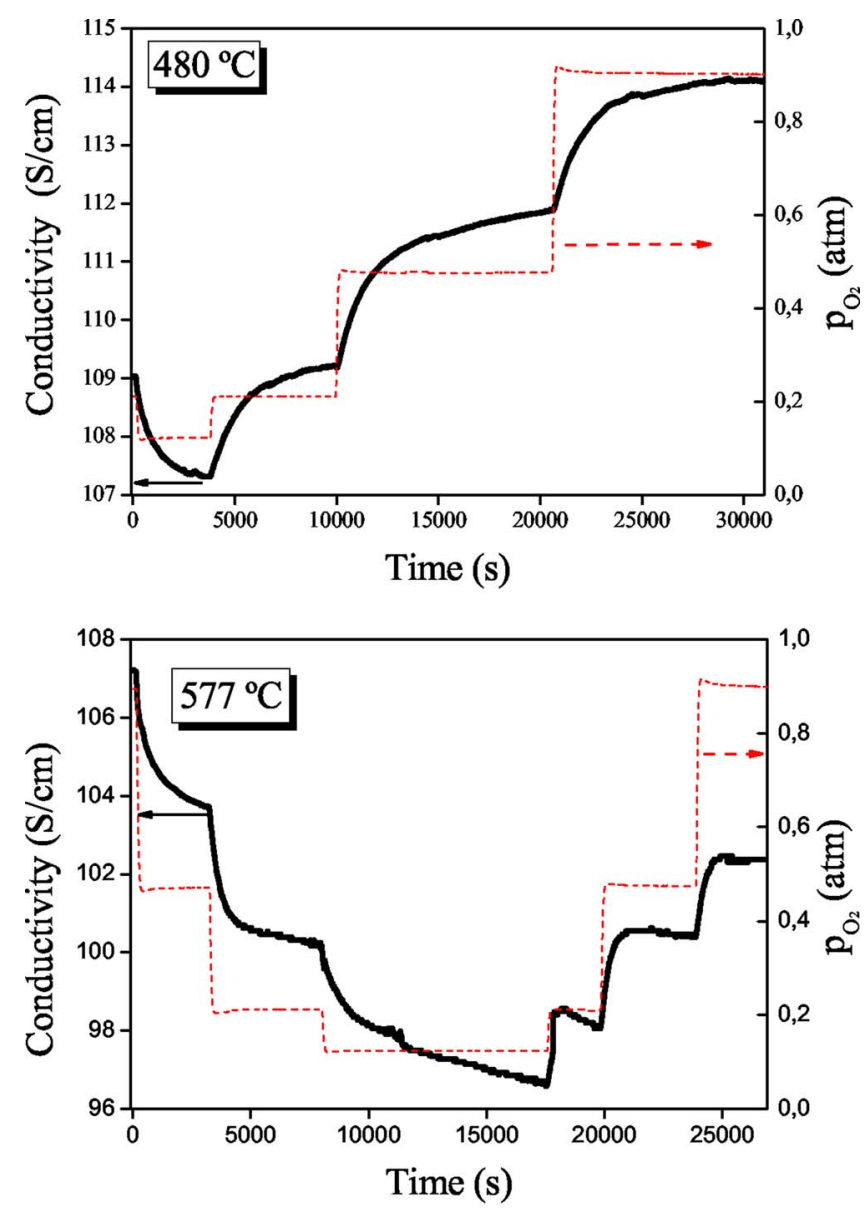

Figure 4. (Color online) Oxygen pressure and conductivity data for gas switches from 0.25 to $0.125,0.125$ to $0.25,0.25$ to 0.50 , and 0.50 to $1 \mathrm{~atm}$ $\mathrm{O}_{2}$ at $480^{\circ} \mathrm{C}$, and the three reduction plus the three oxidation steps at $580^{\circ} \mathrm{C}$ for the $335 \mathrm{~nm}$ LNO film grown on STO.

the reported values to date for single-crystal samples along the $a-b$ plane $($ maximum $\approx 200 \mathrm{~S} / \mathrm{cm}){ }^{36}$ This fact seems to confirm the high quality of our samples. The larger conductivity of the films compared to the ceramic samples can be easily understood by taking into account the anisotropic conductivity properties and thus, that conductivity along the $a-b$ plane for the oriented thin films is higher than that in polycrystalline ceramic (with randomly oriented grains). Nevertheless, the physical phenomena giving rise to a conductivity larger than that in single crystals is still unknown. The high conductivity of very thin films in comparison with $a-b$ plane, single-crystal conductivity could be an effect of the film strain induced by the substrate, as already observed in isostructural $\mathrm{La}_{2} \mathrm{CuO}_{4}$ phase, where superconducting properties are improved by the substrate-

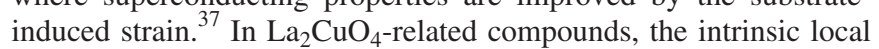
mismatch between the perovskite and rock-salt slabs forming the structure modulates the $\mathrm{Cu}-\mathrm{O}$ distance and is responsible for the electronic doping state and, consequently, the superconducting properties. ${ }^{38}$ In the case of epitaxial thin films of $\mathrm{La}_{2} \mathrm{NiO}_{4}$, both phenomena could thus also take place or coexist. Nevertheless, many other parameters can simultaneously and competitively affect the total transport properties of the LNO films, such as the microstructure and the oxygen content $(\delta)$. Because we are not able to estimate the oxygen content of our samples because of the small volume/mass, added to the presence of an oxide substrate, the contribution of $\delta$ to the conductivity cannot be evaluated.

The conductivity measurements have been complemented with the determination of oxygen exchange parameters. As already described in the Experimental section, the oxygen surface exchange 


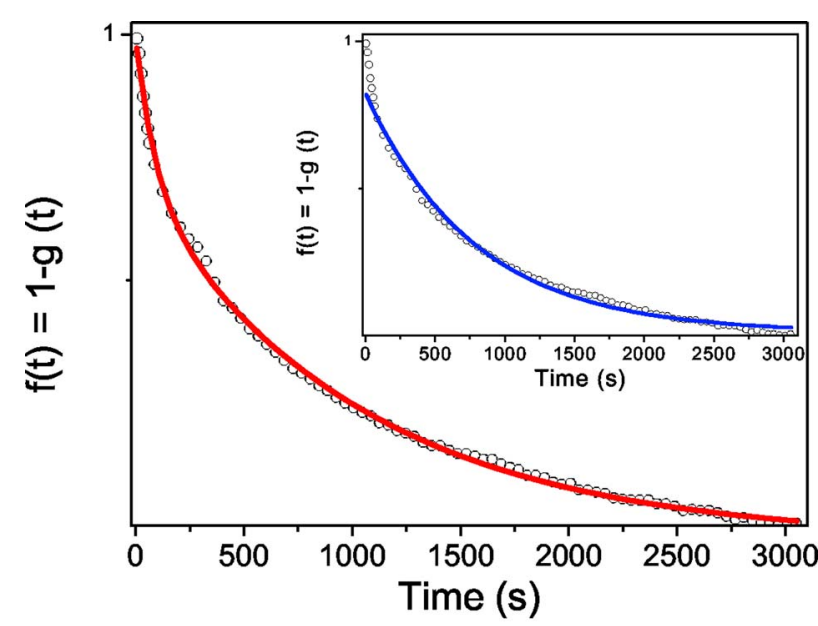

Figure 5. (Color online) A set of ECR data with a gas switch from 1 to 0.50 atm $\mathrm{O}_{2}$ at $580^{\circ} \mathrm{C}$ for the $335 \mathrm{~nm}$ LNO film deposited on STO. The solid curve represents the best fit obtained for the simple model (inset) and the double exponential model.

coefficients of thin $(50 \mathrm{~nm})$ and a thick $(335 \mathrm{~nm})$ films were measured by the electrical conductivity relaxation technique at different temperatures and with different oxygen partial pressure changes. In Fig. $4 \mathrm{a}$ and $\mathrm{b}$ we can see the conductivity evolution of the $335 \mathrm{~nm}$ LNO/STO film by stepping the oxygen partial pressure from 0.125 to $1 \mathrm{~atm}$ of $\mathrm{O}_{2}$ at 480 and $580^{\circ} \mathrm{C}$, respectively. We can observe that the conductivity curves do not have a simple exponential behavior. The presence of a slower diffusion process could be responsible for the apparent anomalies. Figure 5 shows one typical ECR normalized curve corresponding to the $1-0.50 \mathrm{~atm}$ of $\mathrm{O}_{2}$ reduction step measured for the same $335 \mathrm{~nm}$ thick sample at $580^{\circ} \mathrm{C}$. As previously mentioned, a simple exponential function does not satisfactorily fit the experimental results (inset), especially for the short times of the ECR experiments, giving rise to incorrect values of the oxygen exchange coefficient. In order to accurately describe the measured relaxation curves, we introduced a second exponential function to the fitting equation, assuming that an additional process takes place simultaneously, according to

$$
g(t)=1-A_{1} \exp \left(-\frac{t}{\tau_{1}}\right)-A_{2} \exp \left(-\frac{t}{\tau_{2}}\right)
$$

with $A_{1}+A_{2}=1$.

This double-exponential function fitting was more satisfactory, as can be seen in Fig. 5, and therefore two different time constants

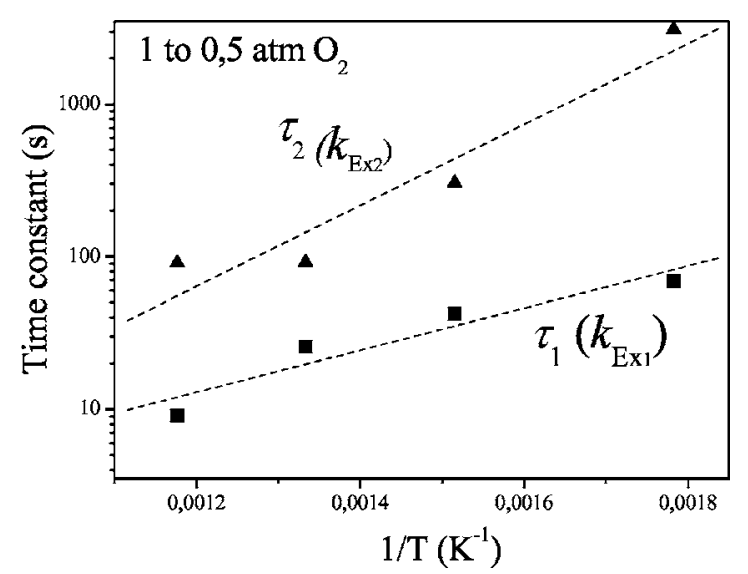

Figure 6. Time constants $\tau_{1}$ and $\tau_{2}$ as a function of temperature for a gas switch from 1 to $0.50 \mathrm{~atm}$ for the $335 \mathrm{~nm}$ LNO film. could be extracted. As an example, the time constants $\tau_{1}$ and $\tau_{2}$ for the 1-0.50 atm step are shown as a function of temperature in Fig. 6. Both $\tau_{1}$ and $\tau_{2}$ show an exponential dependence with reciprocal temperature, which is an indication of a thermally activated process. The apparent activation energy for the process associated to $\tau_{1}$ is about $0.27 \mathrm{eV}$, in agreement with values of about $0.38 \mathrm{eV}$ reported for isotopic oxygen exchange for the same $\mathrm{La}_{2} \mathrm{NiO}_{4}$ films. ${ }^{24}$ The $\tau_{2}$ value is about two orders of magnitude higher than $\tau_{1}$ at low temperatures and one order of magnitude larger at high temperatures. We relate the short time constant $\tau_{1}$ to the film surface exchange process (fast), whereas the large time constant $\tau_{2}$ might be associated either to a slow process limiting the oxygen diffusion at the film-substrate interface or even to a material chemical degradation. Other authors have also used the double-exponential model to better fit the ECR data of $\left(\mathrm{La}_{0.6} \mathrm{Sr}_{0.4}\right)_{0.99} \mathrm{FeO}_{3-\delta},{ }^{39} \mathrm{PrBaCo}_{2} \mathrm{O}_{5+\delta},{ }^{40}$ and $\mathrm{La}_{2} \mathrm{NiO}_{4+\delta}{ }^{20}$ thin films. For Sogaard, ${ }^{39}$ the most realistic interpretation of this second added time constant was related to a chemical diffusion process, and the argument was made that in some cases even a third time constant had to be added to correctly fit experimental results. Kim et al. attributed the double kinetic model to the existence of two independent regions in $\mathrm{PrBaCo}_{2} \mathrm{O}_{5+\delta} 40$ and $\mathrm{La}_{2} \mathrm{NiO}_{4+\delta}{ }^{20}$ films, where the different exchange rates were related to different film microstructures that can induce different chemical reactions at the film surface. In the specific case of LNO films, ${ }^{20}$ Kim et al. considered their material formed by two regions of different surface morphology. The slow exchange kinetics was associated to the expected (001) surface of the $c$-axis oriented LNO films, while the faster exchange kinetics was assigned to the (110) and (100) LNO surface facets, which appeared after the ECR experiments, as detected by XRD.

In Fig. 7 we plot the $k_{\mathrm{Ex}}$ values, extracted from the fast process with time constant $\tau_{1}$, as a function of temperature for both oxidation and reduction processes for the two film thicknesses. The four graphs correspond to the four different final oxygen pressures reached in the reaction chamber after gas switching. No substantial differences between the oxidation and the reduction surface exchange coefficients are observed. On the contrary, a clear difference between the two film thicknesses is detected, $k_{\mathrm{Ex}}$ being higher in the thick than in the thin layer. The difference seems to increase as the final $p_{\mathrm{O}_{2}}$ decreases. In fact, surface exchange coefficients of both thicknesses are similar at $1 \mathrm{~atm}$ of $\mathrm{O}_{2}$. These differences could be basically explained in terms of the larger surface roughness observed in the thick film, which enhances the exchange rate. The increase of the roughness directly enlarges the effective surface. Besides, it could also enhance the oxygen exchange activity, either by the formation of kinks or by the exposure of the exchange gas, to more reactive faces of the LNO structure. The film strain and oxygen content may also vary with thickness; therefore, we cannot rule out an influence of these parameters on the oxygen surface exchange values. Some authors ${ }^{20,31,41}$ have found higher surface exchange coefficients for bulk ceramic samples in comparison with the same material prepared as thin films. This difference can be related to a different orientation present in polycrystalline materials, as also seems to be the case in the layers prepared by Kim et al., but also could relate to the influence of grain boundaries and even grain boundary impurities, which could act in some cases as preferential sites for surface oxygen exchange.

\section{Conclusions}

We have grown high-quality, epitaxial $c$-axis oriented $\mathrm{La}_{2} \mathrm{NiO}_{4+\delta}$ thin films by the PIMOCVD technique. We have prepared films with different thickness onto STO and NGO substrates. High-temperature electrical conductivity measurements have shown that decreasing film thickness enhances the electrical conductivity to values over those found for single crystal. In order to precisely correlate the relation between thickness, strain, microstructure, and conductivity enhancement detected in the present work, the preparation of thinner samples on different substrates and their characterization at different temperatures and oxygen partial pressures is underway. We have 

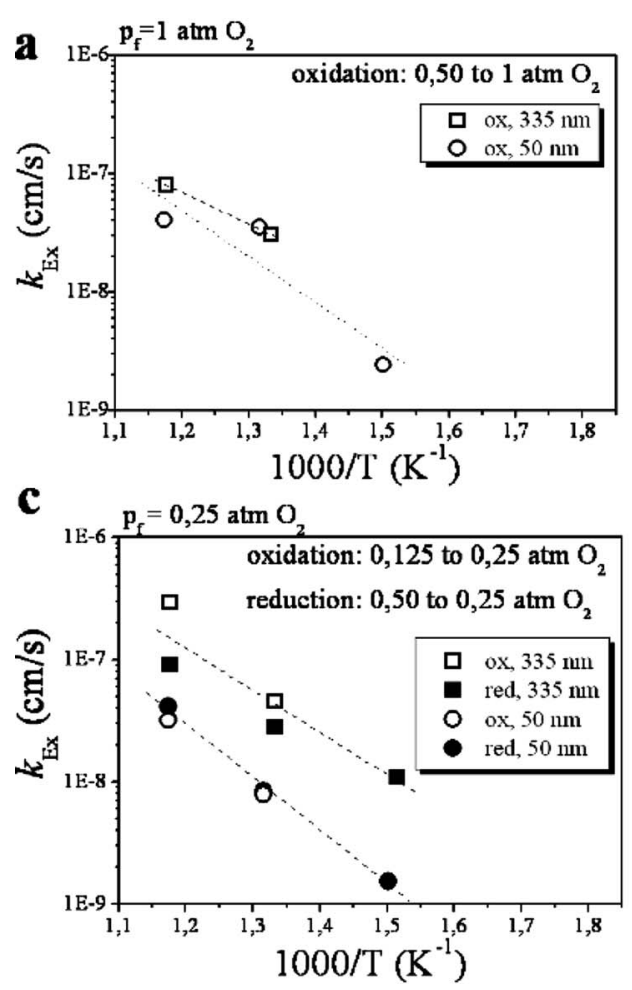
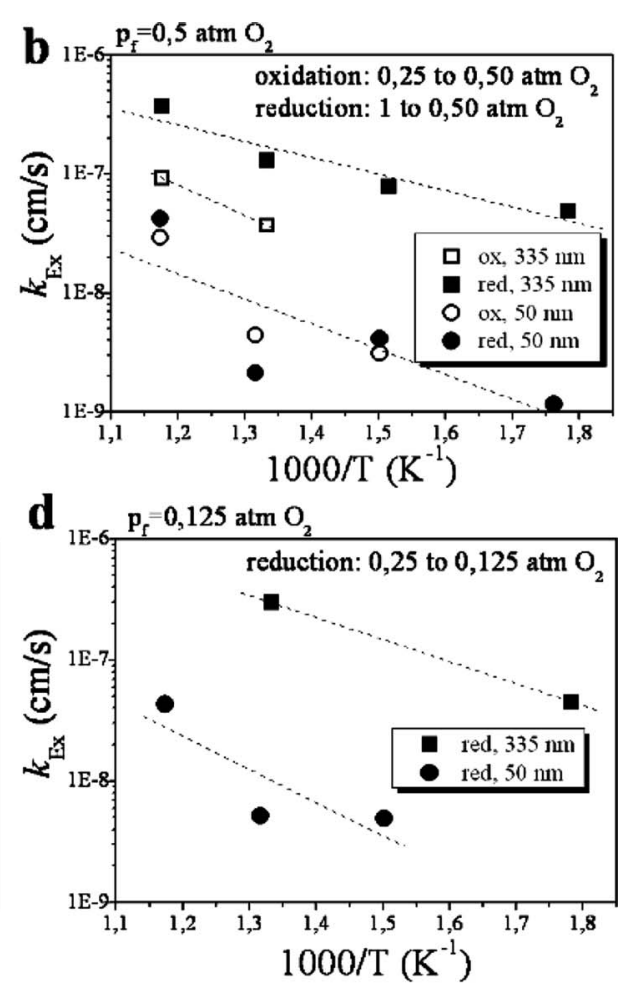

Figure 7. Surface exchange coefficient for the $335 \mathrm{~nm}$ LNO film on STO and the $50 \mathrm{~nm}$ LNO film on NGO as a function of temperature for gas switches, with final oxygen pressure of (a) 1 , (b) 0.50 , (c) 0.25 , and (d) $0.125 \mathrm{~atm}$. The dotted lines serve as eye guidelines for the data corresponding to each LNO film. also studied the chemical surface exchange coefficients by the electrical conductivity relaxation technique. As some ECR data could not be fitted with one single exponential function, we have introduced a double-exponential fitting model. The oxygen surface exchange coefficient is thermally activated and no major differences were found between the oxidation and reduction reaction steps. The thick LNO film presented higher surface exchange coefficient values than the thin one. This could either be an effect of the surface roughness or could be associated to the differences in cell parameters and $\delta$ associated to the different strain in the film, as in the case of electrical conductivity.

\section{Acknowledgments}

This work was partially funded by the MAT03075 project from the Spanish MEC and the Spanish Fuel Cell Network. M.B. acknowledges the I3P program for financial support. The authors thank Dr. M. Sogaard from Ris $\varnothing$ National Laboratory for help and discussions regarding the ECR measurements.

Consejo Superior de Investigaciones Cientificas (CSIC) assisted in meeting the publication costs of this article.

\section{References}

1. X. Chen, N. J. Wu, and A. Ignatiev, J. Eur. Ceram. Soc., 19, 819 (1999)

2. J. Fleig, Fuel Cells, 6, 284 (2006).

3. V. V. Kharton, A. A. Yaremchenko, A. L. Shaula, M. V. Patrakeev, E. N. Naumovich, D. I. Logvinovich, J. R. Frade, and F. M. B. Marques, J. Solid State Chem., 177, 26 (2004).

4. S. J. Skinner and J. A. Kilner, Solid State Ionics, 135, 709 (2000).

5. E. Boehm, J. M. Bassat, M. C. Steil, P. Dordor, F. Muavy, and J. C. Grenier, Solid State Sci., 5, 973 (2003).

6. M. Sayer and P. Odier, J. Solid State Chem., 67, 26 (1987).

7. K. Dembinski, J. M. Bassat, J. P. Coutures, and P. Odier, J. Mater. Sci. Lett., 6, 1365 (1987)

8. V. V. Vashook, S. P. Tolochko, I. I. Yushkevich, L. V. Makhnach, I. F. Kanomyuk, H. Altenburg, J. Hanck, and H. Ullmann, Solid State Ionics, 110, 245 (1998).

9. C. N. R. Rao, D. J. Buttrey, N. Otsuka, P. Ganguly, H. R. Harrison, C. J. Sandberg, and J. M. Honig, J. Solid State Chem., 51, 266 (1984).

10. J. D. Jorgensen, B. Dabrowski, S. Pei, D. R. Richards, and D. G. Hinks, Phys. Rev. $B$, 40, 2187 (1989)

11. L. Minervini, R. W. Grimes, J. A. Kilner, and K. E. Sickafus, J. Mater. Chem., 10, 2349 (2000).

12. J. M. Bassat, P. Odier, A. Villesuzanne, C. Marin, and M. Pouchard, Solid State
Ionics, 167, 341 (2004).

13. J. M. Bassat, F. Gervais, P. Odier, and J. P. Loup, Mater. Sci. Eng., B, 3, 507 (1989).

14. S. Shinomori, M. Kawasaki, and Y. Tokura, Appl. Phys. Lett., 80, 574 (2002).

15. C. Li, T. Hu, H. Zhang, Y. Chen, J. Jin, and N. Yang, J. Membr. Sci., 226, 1 (2003).

16. M. L. Fontaine, C. Laberty-Robert, A. Barnabé, F. Ansart, and P. Tailhades, Ceram. Int., 30, 2087 (2004).

17. M.-L. Fontaine, C. Laberty-Robert, F. Ansart, and P. Tailhades, J. Solid State Chem., 177, 1471 (2004).

18. A. Abrutis, A. Teiserski, G. Garcia, V. Kubilius, Z. Saltyte, Z. Salciunas, V. Faucheux, A. Figueras, and S. Rushworth, J. Membr. Sci., 240, 113 (2004),

19. A. R. Raju, H. N. Aiyer, and C. N. R. Rao, Chem. Mater, 7, 225 (1995).

20. G. Kim, S. Wang, A. J. Jacobson, and C. L. Chen, Solid State Ionics, 177, 1461 (2006).

21. G. T. Kim, S. Wang, A. J. Jacobson, Z. Yuan, and C. Chen, J. Mater. Chem., 17, 13 (2007).

22. V. Faucheux, S. Pignard, and M. Audier, J. Cryst. Growth, 275, e947 (2005).

23. V. Faucheux, S. Pignard, and M. Audier, J. Solid State Chem., 177, 4616 (2004).

24. M. D. Rossell, A. Figueras, G. Van Tendeloo, and J. J. Santiso, Chem. Mater, 19, 4056 (2007).

25. M. W. Den Otter, H. J. M. Bouwmeester, B. A. Boukamp, and H. Verweij, J. Electrochem. Soc., 148, J1 (2001).

26. M. Burriel, G. Garcia, J. Santiso, A. Hansson, S. Linderoth, and A. Figueras, Thin Solid Films, 473, 98 (2005).

27. M. Burriel, G. Garcia, M. D. Rossell, A. Figueras, G. Van Tendeloo, and J. Santiso, Chem. Mater, 19, 4056 (2007).

28. P. Lane, M. Crosbie, P. Wright, P. Donohue, P. Hirst, C. Reeves, C. Anthony, J. Jones, M. Todd, and D. Williams, Chem. Vap. Deposition, 9, 87 (2003).

29. P. Odier, Y. Nigara, and J. Coutures, J. Solid State Chem., 56, 32 (1985).

30. X. J. Chen, S. Soltan, H. Zhang, and H.-U. Habermeier, Phys. Rev. B, 65, 174402 (2002).

31. L. Mogni, J. Fouletier, F. Prado, and A. Caneiro, J. Solid State Chem., 178, 2715 (2005).

32. J. A. Kilner and C. K. M. Shaw, Solid State Ionics, 154-155, 523 (2002)

33. K. Ishikawa, W. Shibata, K. Watanabe, T. Isonaga, M. Hashimoto, and Y. Suzuki, J. Solid State Chem., 131, 275 (1997).

34. G. Amow and S. J. Skinner, J. Solid State Electrochem., 10, 538 (2006).

35. A. Aguadero, J. A. Alonso, M. J. Martínez-Lope, M. T. Fernandez-Díaz, M. J. Escudero, and L. Daza, J. Mater. Chem., 16, 3402 (2006).

36. J. M. Bassat, J. P. Loup, and P. Odier, J. Phys.: Condens. Matter, 6, 8285 (1994).

37. H. Sato, A. Tsukada, M. Naito, and A. Matsuda, Phys. Rev. B, 61, 12447 (2000).

38. S. Agrestini, N. L. Saini, G. Bianconi, and A. Bianconi, J. Phys. A, 36, 9133 (2003).

39. M. Sogaard, Ph.D. Thesis, Ris $\varnothing$ National Laboratory (2006).

40. G. Kim, S. Wang, A. J. Jacobson, Z. Yuan, W. Donner, C. L. Chen, L. Reimus, P. Brodersen, and C. A. Mims, Appl. Phys. Lett., 88, 024103 (2006).

41. L. W. Tai, M. M. Nasrallah, H. U. Anderson, D. M. Sparlin, and S. R. Sehlin, Solid State Ionics, 76, 259 (1995). 